is hoped to maintain and perhaps extend the activi. ties.

As a temporary measure, pending the appointment of a successor to Sir William Bragg, the managers have made the following appointments : The general secretary, Mr. Thomas Martin, on leave of absence with the Ministry of Supply, to be 'resident' in charge of the house; Mr. R. Cory, librarian, to be deputy general secretary; Dr. A. Muller, assistant director of the Davy Faraday Research Laboratory, to be acting director.

\section{American Philosophical Society Research Grants}

THE Yearbook of the American Philosophical Society, 1940, covers the year January 1-December 31,1940 , and in addition to the minutes of the executive sessions includes the reports of standing committees as well as of the Special Committee on Education and Participation in Science, the purposes of which are to conduct a survey of amateur science in the Philadelphia area and to stimulate participation of laymen in scientific research. Almost half the volume is occupied by the report of the Standing Committee on Research, which includes reports from recipients of grants from the Penrose Fund, from which 107 grants, totalling some 360,750 dollars, were awarded during the year. Of these, two were in mathematics, five in astronomy and astrophysics, seven in physics and eleven in chemistry and geochemistry. Eight grants were made in zoology, four in genetics and cytology, nine in botany, eight in physiology, one in biochemistry, four in pathology and medicine, ten in American and modern history, one in political science, four in archæology, and four in ethnology. The distribution is roughly proportional to the number of applications from the different classes, and the Committee on Research has always attempted to make the grants to the most worthy applicants without reference to the subjects represented. Further, since the funds at the disposal of the Committee are insufficient to make long-continuing grants, the policy has been to help start or finish worthy projects rather than to furnish continuing support, nor have grants been made to pay in whole or part the salaries of members of the staff of any institution, nor in general to pay living expenses of applicants.

\section{New Exchange-Area Cable}

An article by N. V. Firth (Bell Lab. Rec., 20, No. 8 ; April, 1942) describes an investigation carried out to determine whether the most economical series of new telephone cables would result from reductions in the diameters of cables having 24- and 26-gauge conductors, together with the addition of a cable with conductors of a smaller size such as 28-gauge, or whether the 24- and 26-gauge should be superseded by 25- and 27-gauge. Experimental lengths of cable were manufactured with conductors of each of these sizes, all with reduced amounts of pulp insulation. Studies of dielectric strength were made on each type. Thickness of pulp insulations used for full-sized cables containing 1,515 pairs of 24-gauge, 1,818 pairs of 25 -gauge, 2,121 pairs of 26 -gauge, 2,424 pairs of 27 -gauge, or 3,030 pairs of 28 -gauge provide satisfactory dielectric strength. No major alterations in the cable manufacturing equipment would be required for the introduction of any of these new types. A study of overall savings indicated that the greatest advantage would result by retaining the four existing standard gauge sizes and increasing the maximum number of pairs in 24-gauge and 26-gauge cables to 1,515 and 2,121 pairs respectively. Thinner insulations of the new cables have somewhat lower dielectric strengths than those of the previously standard 24. and 26-gauge pulp-insulated cables. Tests indicate, however, that they are at least as good as the corresponding strip-insulated 24- and 26-gauge cables which form a large part of the existing plant.

For assembling the required number of 24- or 26gauge pairs into cables the method is the same as that for the previously standard 24- or 26-gauge designs. Cables ranging in sizes from 11 pairs to 101 pairs are stranded as a single unit. Those larger than 101 pairs and up to 303 pairs are first built up in small units of 50 or 51 pairs which are then assembled in long spirals to form the completed cable. All sizes larger than 303 pairs are formed similarly from units of 101 pairs each. The colour code for the groupings of pairs remains the same in the new designs as in other unit type cable in recent years. The larger number of pairs obtainable in the full sizes of these new designs will in some instances prove economical in plant rearrangements incident to central-office cutovers and should be advantageous in making additions to plant where there is underground conduit congestion. The major savings, however, are expected from the reductions in sheath diameters for cables of the same numbers of pairs as formerly.

\section{Earthquake Recorded at Kew}

The strong earthquake of May 14 in Ecuador (NATURe, May 23, p. 578, and May 30, p. 607) was recorded at Kew Observatory, $i P$ appearing on all components of the seismograph at $02 \mathrm{~h} .25 \mathrm{~m}$. 5ls. U.T. This was compressional. A full suite of pulses followed and the shock finished recording at about 07h. $45 \mathrm{~m}$. U.T. The estimated epicentral distance was $9,520 \mathrm{~km}$. All interpretations are tentative.

\section{Announcements}

Mr. Willtam Morrish Selvey is to continue for another year as president of the Institute of Fuel. Mr. Selvey, who has been connected with the Institute since its inception, and has for several years been chairman of the Council, took office as president in October 1941.

THE following appointments and promotions in the Colonial Service have recently been made: H. D. Jordan, agricultural officer, Sierra Leone; A. G. Beattie (assistant director of agriculture), deputy director of agriculture, Nigeria; L. D. Cleare (entomologist), deputy director of agriculture, British Guiana; R. M. Davies (senior agricultural officer, Tanganyika Territory), senior agricultural officer, Zanzibar ; I. E. James (principal agricultural officer), assistant director of agriculture, Nigeria; D. H. Urquhart (senior agricultural officer), principal agricultural officer, Nigeria.

Mr. T. SHEPPARD has produced an important catalogue of the Bronze Age implements in the Mortimer Museum, Hull (Hull Museum Pub., No. 213). There are a number of illustrations. Hull has been fortunate in the past in the matter of acquisitions and its Bronze Age collections are important. Prehistorians, therefore, fwill be grateful for this new catalogue. 